\title{
Combined effects of XAF1 and TRAIL on the apoptosis of lung adenocarcinoma cells
}

\author{
FUQUAN ZHANG $^{1 *}$, DONGLAI CHEN $^{2 *}$, WENTAO YANG $^{1}$, SHANZHOU DUAN $^{1}$ and YONGBING CHEN ${ }^{1 *}$ \\ ${ }^{1}$ Department of Cardiothoracic Surgery, The Second Affiliated Hospital of Soochow University, \\ Suzhou, Jiangsu 215004; ${ }^{2}$ Department of Thoracic Surgery, Shanghai Pulmonary Hospital, \\ Tongji University School of Medicine, Shanghai 200433, P.R. China
}

Received May 24, 2016; Accepted April 10, 2017

DOI: $10.3892 /$ etm.2019.7491

\begin{abstract}
This study aimed to investigate the effects and mechanisms of X-linked inhibitor of apoptosis protein (XIAP)-associated factor 1 (XAF1) and tumor necrosis factor-related apoptosis-inducing ligand (TRAIL) on the apoptosis of A549 lung adenocarcinoma cell lines. Recombinant lentiviral vector of Ad5/F35-XAF1 and controlled lentiviral vector of Ad5/F35-Null were transfected into A549 cells at same multiplicity of infection (MOI), respectively. Based on whether recombinant human TRAIL (rhTRAIL) was added or not, cells were divided into different groups as follows: XAF1 group, XAF1 + TRAIL group, XAF1-Null group, and XAF1-Null + TRAIL group. Following culturing for $48 \mathrm{~h}$, the mRNA and protein expression levels of related genes were determined by reverse transcription-quantitative polymerase chain reaction and western blotting analyses, respectively. Cell proliferationand cell apoptosis were detected by MTT assay and Annexin V-FITC/PI double staining, respectively. Xenograft mice models were established with A549 lung adenocarcinoma cells and treated with recombinant virus Ad5/F35-XAF1 and controlled virus Ad5/F35-Null for immunohistochemical analysis. Expression levels of XAFl at the mRNA and protein levels were significantly higher in the XAF1 group and XAF1 + TRAIL groups when compared with the levels in the other groups $(\mathrm{P}<0.05)$. Cleavage of apoptosis-associated proteins, poly ADP-ribose polymerase and caspase-3, was noted in the XAF1 + TRAIL group, whereas they were not detected in other groups. Apoptosis rates of A549 cells in the XAF1, Null + TRAIL and $\mathrm{XAFl}+$ TRAIL groups were significantly higher than those in
\end{abstract}

Correspondence to: Dr Yongbing Chen, Department of Cardiothoracic Surgery, The Second Affiliated Hospital of Soochow University, 1055 Sanxiang Road, Suzhou, Jiangsu 215004, P.R. China E-mail: chentongt@sina.com

*Contributed equally

Key words: X-linked inhibitor of apoptosis protein-associated factor 1, tumor necrosis factor-related apoptosis-inducing ligand, lung adenocarcinoma cell lines, apoptosis the NOR and Null groups $(\mathrm{P}<0.05)$. Apoptotic rates were highest in the XAF1 + TRAIL group. In conclusion, these findings suggest that combined use of XAF1 and TRAIL may synergistically induce the apoptosis of A549 lung adenocarcinoma cells.

\section{Introduction}

Lung cancer is one of the primary causes of cancer associated mortalities worldwide and $>80 \%$ of lung cancer cases are non-small cell lung cancer (NSCLC). In 2008, >1.6 million people were diagnosed with lung cancer, accounting for $13 \%$ of all newly diagnosed cancer cases and 1.4 million succumbed to lung cancer, which accounted for $18 \%$ of all cancer associated mortalities (1).

Apoptosis is a process of programmed cell death, which maintains a healthy survival/death balance in metazoan cells. Apoptosis is a key regulator of tissue homeostasis and is tightly regulated by the interactions of activating and inhibitory pathways (2). Aberrant inhibition of cellular apoptosis may result in various diseases, including lung cancer (3). The mechanism of apoptosis is complicated and is regulated at many levels. The signals of carcinogenesis regulate the central control points of the apoptotic pathways, including inhibitor of apoptosis (IAP) proteins. Inhibition of apoptosis has an important role in the development of lung cancer (4). It has been reported that $\mathrm{X}$-linked IAP (XIAP)-associated factor 1 (XAF1) is able to inhibit proliferation and induce apoptosis in tumor cells when combined with XIAP directly (5). Furthermore, our previous study indicated that XAF1 induced apoptosis in lung cancer cells (6). Tumor necrosis factor-related apoptosis-inducing ligand (TRAIL) specifically induces apoptosis of tumor cells, while no toxicity effect on normal cells has been demonstrated (7-9). In this study, recombinant adenoviral vectors were transiently transfected into lung adenocarcinoma cells to recover the expression of XAF1. Apoptotic effects of XAF1 and TRAIL on A549 lung adenocarcinoma cell lines were investigated, which may provide an experimental basis for the application of this treatment in patients with lung cancer.

\section{Materials and methods}

Reagents. Recombinant virus Ad5/F35-XAF1 and controlled virus Ad5/F35-Null were constructed by Shanghai R\&S 
Biotechnology Co., Ltd. (Shanghai, China) and stored in a laboratory (Ruijin Hospital, Shanghai Jiaotong University School of Medicine, Shanghai, China). rhTRAIL was bought from Peprotech, Inc. (Rocky Hill, NJ, USA). Reverse transcription system was provided by Promega Corp. (Madison, WI, USA). Primers of XAF1 and $\beta$-actin and $2 \mathrm{X}$ Tap PCR MasterMix were from Sangon Biotech Company (Shanghai, China). BCA protein assay kit was bought from Pierce (Thermo Fisher Scientific, Inc., Waltham, MA, USA). Rat anti-human XAF1 primary antibody was supplied by Abcam (Cambridge, UK). Poly ADP-ribose polymerase (PARP) and capase-3 antibodies were purchased from Cell Signaling Technology, Inc., (Danvers, MA, USA). Mouse anti-rat secondary antibody was bought from Santa Cruz Biotechnology, Inc., (Dallas, TX, USA). MTT and DMSO were purchased from Sigma-Aldrich (Merck KGaA, Darmstadt, Germany). Annexin V-fluorescein isothiocyanate (FITC)/propidium iodide (PI) Apoptosis Detection Kit and flow cytometry kits were supplied by BD Company (Franklin Lakes, NJ, USA).

Experimental animals. A total of 20 four-week old female BALB/c nude mice were provided by Animal Experimental Centre of Shanghai Institutes for Sciences (Shanghai, China). All animal experiments were approved by and conducted according to the ethical guidelines of Medicine Laboratory Animal Ethics Committee of Shanghai Jiaotong School of Medicine (Shanghai, China).

Cell transfection. A549 cells were cultured in RPMI 1640 complete medium (Gibco; Thermo Fisher Scientific, Inc.) supplemented with $10 \%$ FBS for $24 \mathrm{~h}$. Adenovirus vectors carrying XAF1 and null genes, respectively, were transfected into lung adenocarcinoma A549 cells (NOR cells) using Lipofectamine 2000 (Invitrogen; Thermo Fisher Scientific, Inc.). Cells were divided into different groups based on transfection with or without TRAIL: XAF1 group, XAF1 + TRAIL group, Null group, and Null + TRAIL group, NOR group, and Null + TRAIL group. All transfected cells were cultured in RPMI 1640 serum-free medium with $100 \mathrm{PFU} / \mathrm{ml}$ multiplicity of infection (MOI). The blank normal control group was cultured without any lentiviral vector transfection. Differing concentrations of TRAIL (25, 50 and $100 \mathrm{ng} / \mathrm{ml}$, respectively) were added to the associated groups. Following incubation for $4 \mathrm{~h}$, the medium as replenished with RPMI 1640 complete medium supplemented with $10 \%$ FBS. Cells were collected after culturing for $48 \mathrm{~h}$ at $37^{\circ} \mathrm{C}\left(5 \% \mathrm{CO}_{2}\right)$ until collection.

Reverse transcription-polymerase chain reaction (RT-PCR) analysis. To detect the expression levels of XAF1, total RNA $(10 \mu \mathrm{g})$ was extracted from cells using TRIzol, according to the manufacturer's instructions (Invitrogen; Thermo Fisher Scientific, Inc.). The cDNA was synthesized with a SensiMix ${ }^{\mathrm{TM}}$ SYBR-Green One-Step kit (Quantace; Bioline Reagents, London, UK), according to the manufacturer's protocols. The cDNA was treated with polymerase inhibitor and stored in fluid nitrogen cryopreservation to prevent degradation. The RT reaction was performed at $42^{\circ} \mathrm{C}$ for $30 \mathrm{~min}$. 2xTaq PCR MasterMix was used for PCR and the total reaction volume was $20 \mu \mathrm{l}$. Primers of XAF1 were: 5'-TCCGCAATTCATGCT CCACGAGTCCTACTG-3' (forward) and 5'-ACGCGTCGA
CAAACTCTGAGTCTGGACAAC-3' (reverse). Primers of $\beta$-actin were: 5'-ATCTGGCACCACACCTTCTACAATGAG CTGC-3' (forward) and 5'-CGTCATACTCCTGCTTGCTGA TCCACATCTGC-3' (reverse) (Shanghai R\&S Biotechnology Co., Ltd.). Cycling conditions of PCR were: $95^{\circ} \mathrm{C}$ for $3 \mathrm{~min}$, followed by 32 cycles at $95^{\circ} \mathrm{C}$ for $45 \mathrm{sec}, 57^{\circ} \mathrm{C}$ for $45 \mathrm{sec}$, and $72^{\circ} \mathrm{C}$ for $45 \mathrm{sec}$, and final extension at $72^{\circ} \mathrm{C}$ for $8 \mathrm{~min}$. PCR products were detected by $2 \%$ agarose gel electrophoresis and analyzed via the Odyssey Infrared Imaging System (Li-Cor Biosciences, Lincoln, NE, USA).

Western blot analysis. Total proteins were extracted using radioimmunoprecipitation assay lysis buffer and phenylmethylsulfonyl fluoride at a ratio of 200:2, and the concentration was quantified by BCA kit. Proteins were separated by $10 \%$ SDS-PAGE, transferred to membrane, and subsequently blocked with $5 \%$ skim milk. Blots were incubated with specific primary antibodies against $\beta$-actin (cat no. ab8227), XAF1 (cat no. ab217178), caspase-3 (cat no. 9662) and PARP (cat no. 9542; all 1:1,000), at $4^{\circ} \mathrm{C}$ overnight. Following washing three times by PBS, the secondary antibodies were added and shaken for $2 \mathrm{~h}$ at room temperature. The membrane was developed and exposed by adding electrochemiluminescence reagent, and the images were analyzed using the gel imaging system. Relative expression was analyzed using Image J 2.0 software (National Institutes of Health, Bethesda, MD, USA).

MTT assay. Cells were seeded at the density of $1 \times 10^{4}$ cells/well. After $48 \mathrm{~h}$ incubation at $37^{\circ} \mathrm{C}$, MTT $(5 \mathrm{mg} / \mathrm{ml}$ in DMSO) was added to the wells ( $20 \mu \mathrm{l} /$ well) after discarding the supernatant liquid and incubated for an additional $4 \mathrm{~h}$. DMSO-treated cellswere used as control. Following this, MTT was replaced by DMSO (100 $\mu \mathrm{l} /$ well). Absorbance (A value) was measured at the wavelength of $570 \mathrm{~nm}$ after shaking for $15 \mathrm{~min}$ in the dark. Cell proliferation was calculated as follows: Cell proliferation ratio $=($ experiment $\mathrm{A}$ value-control $\mathrm{A}$ value $) /$ control $\mathrm{A}$ value $\mathrm{x} 100 \%$. Each group was exposed to different concentrations and replicated three times to calculate an average.

Flow cytometry. Transfected A549 lung adenocarcinoma cells $\left(1 \times 10^{5}\right.$ cells/well) were cultured and divided into different groups, as outlined. Annexin V-FITC and PI staining fluid were added after incubation at $37^{\circ} \mathrm{C}$ for $48 \mathrm{~h}$. Flow cytometry was used to detect apoptosis of cells in each group. Annexin $\mathrm{V}$-positivity indicates the apoptotic cells are in early stage, while PI positive means the cells are necrotic. Annexin V and PI-double positive cells are late apoptotic cells.

Xenograft mice model. A total of 20 four-week old female $\mathrm{BALB} / \mathrm{c}$ nude mice were divided into four groups (XAF1, XAF1 + TRAIL, Null and Null + TRAIL), as outlined. A549 cell lines (with $1 \times 10^{6} / 0.1 \mathrm{ml}$ PBS) were injected into the right side of the back ribs of each mouse. When the tumor could be observed by naked eyes, tumor size was measured using a caliper every 7 days. Tumor volume (V) was calculated according to the following formula: $V=V=4 / 3 \pi x L / 2 x(w / 2) 2$; where $\mathrm{L}$ is a relatively shorter diameter and $\mathrm{w}$ is a relatively longer diameter. Animals were sacrificed on day 30 after injection, and their tumors were weighed and harvested. Images were captured of the tumor specimens, which were subsequently 


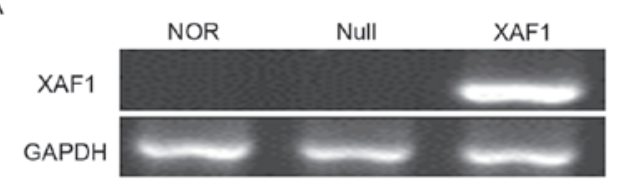

C

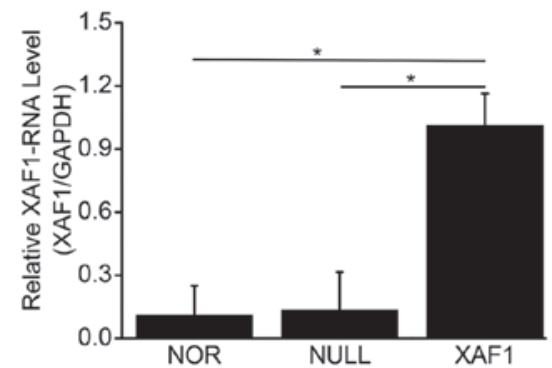

XAF 1

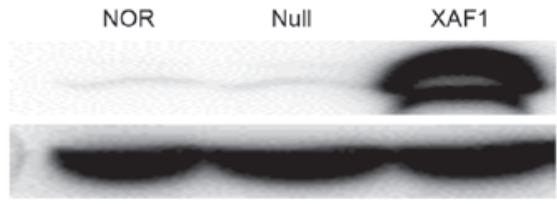

D

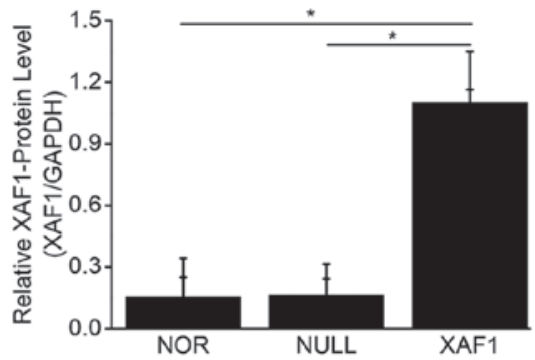

Figure 1. Expression levels of XAF1 mRNA and protein after transient transfection in A549 cells. (A) Reverse transcription-polymerase chain reaction was used to detect the expression of XAF1. (B) Western blot was used to detect the protein expression of XAF1. XAF1, X-linked inhibitor of apoptosis protein-associated factor 1; NOR, normal. (C and D) Quantitative analysis of the expression levels. * $\mathrm{P}<0.05$.

fixed using neutral formaldehyde and paraffin-embedded for further immunohistochemical analysis.

Immunohistochemical (IHC) analysis. Tissue sections were kept at $80^{\circ} \mathrm{C}$ for $30 \mathrm{~min}$ and subsequently de-paraffinized and rehydrated to retrieve antigen and block peroxidase. Following blocking with non-immune sheep serum, rat anti-human XAF1 primary antibody (1:800; cat no. ab217178; Abcam) was added and incubated at $4{ }^{\circ} \mathrm{C}$ overnight. Following this, tumor sections were incubated with horseradish peroxide-conjugated goat anti-rabbit immunoglobulin G (1:1,000; cat no. cw0105; Beijing Cowin Biotech Co., Ltd., Beijing, China) and enough peroxidase substrate was added. A light microscope was used to control staining and PBS was used to terminate the reaction. Nuclei were stained with hematoxylin. Following dehydration and coating with resinene resin, XAF1 IHC slices were observed under a light microscope. Cells stained brown were deemed as positive.

Statistical analysis. Data are expressed as the mean \pm standard deviation. SPSS 16.0 statistical software (SPSS, Inc., Chicago, IL, USA) was used for statistical analysis. Analysis of variance (ANOVA) with Tukey's post hoc test was used for comparisons among multiple groups. $\mathrm{P}<0.05$ was considered to indicate a statistically significant difference.

\section{Results}

mRNA and protein expression of XAF1 in A549 cells. To explore whether the expression of XAF1 changed in transfected cells, RT-PCR and western blot analysis were employed to detect XAF1 in the different groups of A549 cells. As shown in Fig. 1A, XAF1 mRNA was markedly increased in A549 cells after $48 \mathrm{~h}$ of XAF1 group, and XAF1 protein was also upregulated in the XAF1 group when compared with the NOR and Null groups (Fig. 1B). Quantitative analysis of gene and the western blot data were presented respectively (Fig. 1C and D). These results showed that XAF1 was significantly increased after transfection with Ad5/F35-XAF1 vector in A549 cells $(\mathrm{P}<0.05)$.

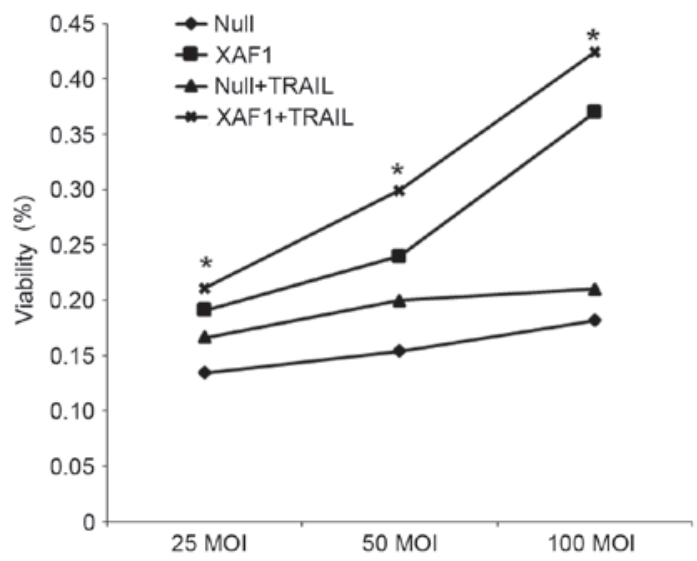

Figure 2. Proliferation of A549 cells after transfection in the four different groups. Proliferation rates of A549 cells in XAFl + TRAIL group were significantly higher than in the XAF1 group $\left({ }^{*} \mathrm{P}<0.05\right)$. XAF1, X-linked inhibitor of apoptosis protein-associated factor 1; TRAIL, tumor necrosis factor-related apoptosis-inducing ligand; MOI, multiplicity of infection.

Cell proliferation. To investigate the effect of XAF1 and TRAIL on cell proliferation, MTT assay was applied to detect the rate of proliferation in cells of each group. As shown in Fig. 2, the inhibiting effect on the proliferation of A549 cells demonstrated a positive correlation with the concentration of XAF1 in the XAF1 + TRAIL group. Among the Null, $\mathrm{XAF} 1$ and Null groups, the inhibition ratio of proliferation was significantly higher in XAF1 group than in the other groups at the same concentration of TRAIL $(\mathrm{P}<0.05)$. These findings indicated that TRAIL and different concentrations of XAF1 were able to inhibit the proliferation of A549 cells in a dose-dependent manner.

Cell apoptosis by XAF1. To detect how XAF1 regulated apoptosis in A549 cells, the Annexin V-FITC/PI double staining method was used to assess the different groups. Among the six experimental groups, compared with the XAFl and Null groups, the apoptosis rate in the XAF1 + TRAIL group was significantly higher $(\mathrm{P}<0.05)$, whereas no statistically difference was 
A
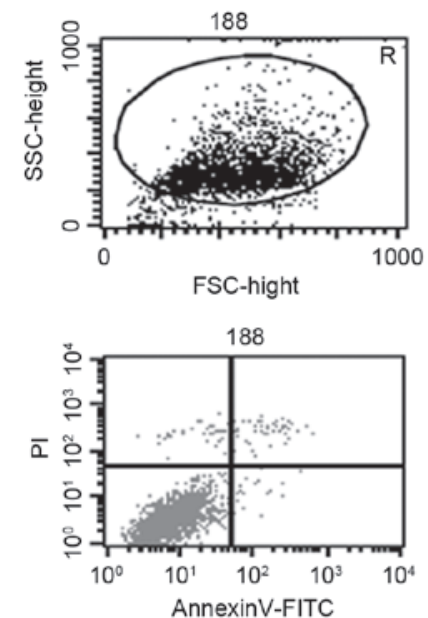

Sample ID: A549-NOR

\begin{tabular}{rr} 
Quad & $\%$ Gated \\
\hline UL & 1.59 \\
UR & 2.71 \\
LL & 94.57 \\
LR & 1.14
\end{tabular}

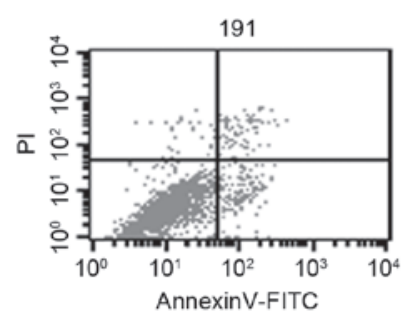

Sample ID: A549-NOR+TR

\begin{tabular}{cr} 
Quad & $\%$ Gated \\
\hline UL & 1.82 \\
UR & 3.71 \\
LL & 87.25 \\
LR & 7.22
\end{tabular}

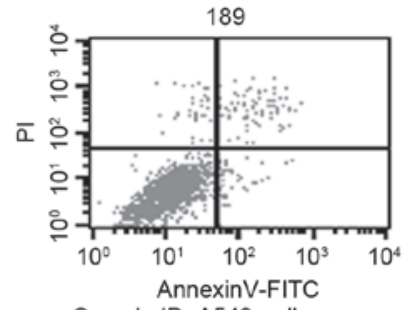

Sample ID: A549-null
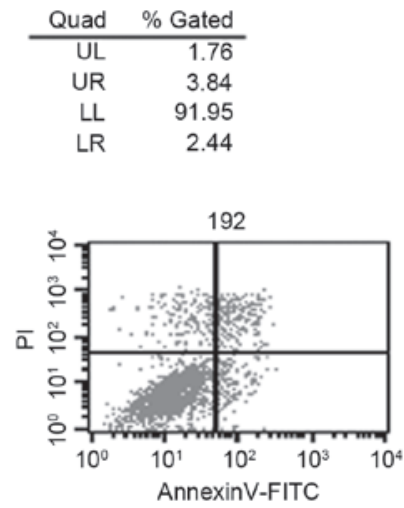

Sample ID: A549-null+TRAIL

\begin{tabular}{cr} 
Quad & \% Gated \\
\hline UL & 7.77 \\
UR & 10.36 \\
LL & 74.95 \\
LR & 6.92
\end{tabular}

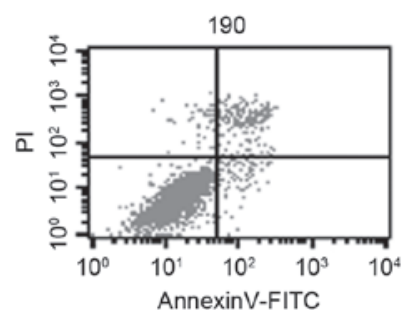

Sample ID: A549-XAF1

\begin{tabular}{rr} 
Quad & $\%$ Gated \\
\hline UL & 2.54 \\
UR & 9.51 \\
LL & 83.41 \\
LR & 4.53
\end{tabular}

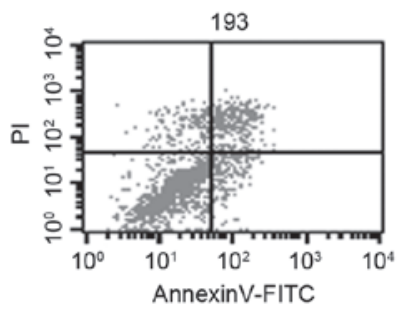

Sample ID: A549-XAF1+TRAIL

\begin{tabular}{cr} 
Quad & $\%$ Gated \\
\hline UL & 7.67 \\
UR & 17.04 \\
LL & 66.06 \\
LR & 9.22
\end{tabular}

B

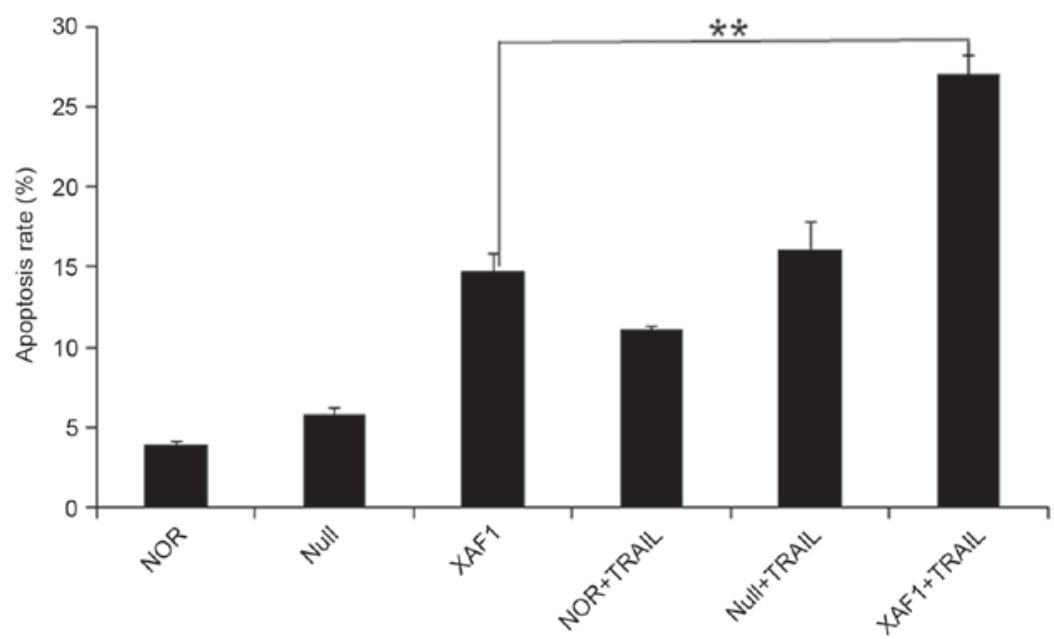

Figure 3. Apoptosis rate of A549 cells after transfection in the different groups. (A) Flow cytometry was used to detect the apoptosis of different groups of cells. Representative flow cytometry results are shown. (B) Apoptosis rate of different groups of cells compared with the NOR group $\left({ }^{* *} \mathrm{P}<0.01\right)$. XAF1, X-linked inhibitor of apoptosis protein-associated factor 1; TRAIL, tumor necrosis factor-related apoptosis-inducing ligand; NOR, normal; FITC, fluorescein isothiocyanate; PI, propidium iodide; UL, upper left quadrant; UR, upper right quadrant; LL, lower left quadrant; LR, lower right quadrant.

observed between the Null + TRAIL and NOR groups (Fig. 3). These results demonstrated that TRAIL was able to promote the apoptotic effect of Ad5/F35-XAF1 on A549 cells. These findings suggested that a combination of TRAIL and XAF1 may induce cell apoptosis coordinately, with TRAIL enhancing the sensitivity of XAF1 to induce A549 cell apoptosis. 


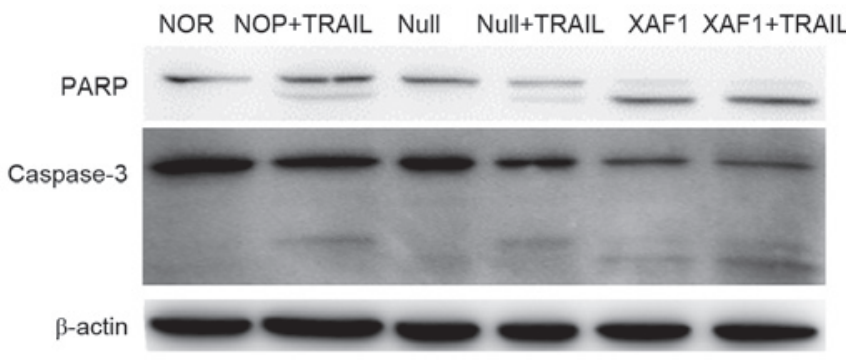

Figure 4. Western blot analysis to detect the expression of PARP and caspase-3 protein in cells of the different groups. XAF1, X-linked inhibitor of apoptosis protein-associated factor 1; TRAIL, tumor necrosis factor-related apoptosis-inducing ligand; NOR, normal; PARP, poly ADP-ribose polymerase.

Expression of apoptosis-related proteins. To detect changes in the expression of apoptosis-related proteins, western blot analysis was used to detect the expression levels of PARP, caspase-3 and XAF1 in A549 cells after transfection with Ad5/F35-XAF1 (MOI 150) for $4 \mathrm{~h}$. As shown in Fig. 4, the results showed that the XAF1 + TRAIL induced marked PARP and caspase- 3 cleavage compared with other groups (Fig. 4). No notable difference was observed between the NOR and Null groups.

Transplanted tumor model of nude mice. To determine the impact of XAF1 following combined treatment with TRAIL in vivo, a transplanted tumor model of nude mice was generated. Visible tumor tissue was formed 14 days after the injections in the four groups of nude mice (XAF1, XAF1 + TRAIL, Null and Null + TRAIL). Subcutaneously transplanted tumors were stripped from nude mice 30 days after injection (Fig. 5A). Growth rates of subcutaneously transplanted tumors in the XAF1 and XAF1 + TRAIL groups were significantly lower than those of the Null and Null + TRAIL groups $(\mathrm{P}<0.05)$. Growth rates of subcutaneously transplanted tumors in the XAF1 + TRAIL group were significantly lower than those of the XAF1 group $(\mathrm{P}<0.05)$ and no significant difference was observed between the Null and Null + TRAIL groups (Fig. 5B). These results indicate that XAF1 + TRAIL inhibited the growth of tumor cells in the murine xenograft model.

Expression of XAF1 protein on transplanted tumor tissue biopsies. To determine the expression of XAF1 protein in vivo, tumor tissue biopsies were performed. According to IHC analysis, the expression of XAF1 protein was significantly higher in the XAF1 and XAF1 + TRAIL groups when compared with the Null and Null + TRAIL groups $(\mathrm{P}<0.05$; Fig. 6). The results indicate that XAF1 may have important roles in inhibiting the growth of xenograft.

\section{Discussion}

Lung cancer, which is one of the most common malignant tumors in China, has become the major cause of cancer-associated mortality due to its gradually increasing morbidity and mortality rates (10). Multiple studies have confirmed that inhibition of cell apoptosis is common and dysregulation of cell apoptosis has an important role in tumorigenesis and

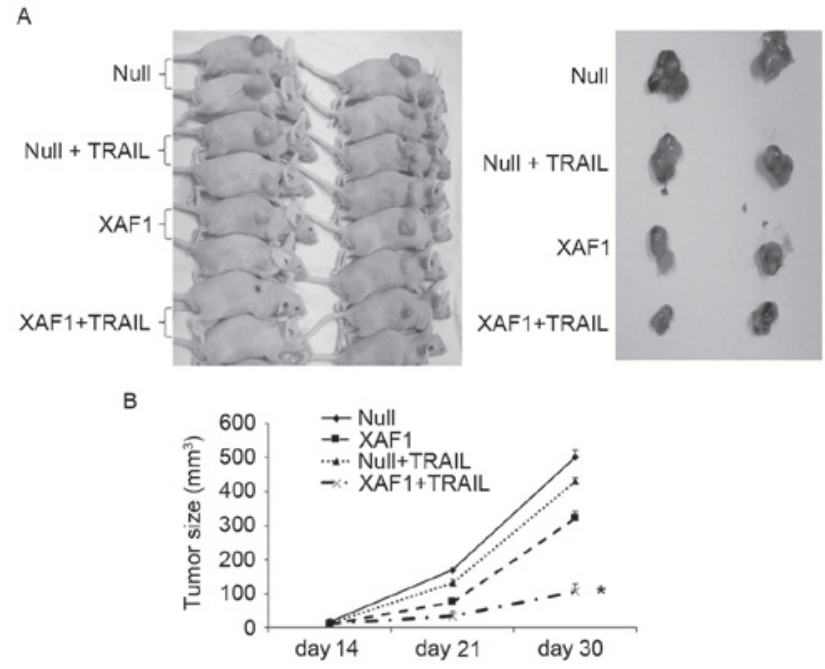

Figure 5. Tumor samples after subcutaneous transplantation of different groups of cells in nude mice. (A) Images of the different tumor samples following transplantation of different groups of cells. (B) Tumor size after subcutaneous transplantation in nude mice. The growth rate of subcutaneously transplanted tumors in the XAF1 + TRAIL group was significantly lower than in the XAF1 group. ${ }^{*}<<0.05$ compared to XAF1 and NULL+TRAIL group; ${ }^{\text {P }}<0.05$ compared to NULL and NULL+TRAIL group. XAF1, $\mathrm{X}$-linked inhibitor of apoptosis protein-associated factor 1; TRAIL, tumor necrosis factor-related apoptosis-inducing ligand.

tumor progression $(3,11)$. XAF1 is a newly discovered type of XIAP antagonistic protein that was via a yeast two-hybrid system (12). XAF1 is able to directly degrade XAP1 via mitochondrial pathways (13). XAF1 is a tumor suppressor gene that has been demonstrated to decrease multiple tumor cells and tissues in humans (14). Numerous patients with terminal lung cancer who are unsuitable for surgery are administered with conventional chemotherapeutics, which kill tumor cells and normal tissue cells indistinctively, with serious side effects. Therefore, the present study aimed to investigate the combined effects of XAF1 and TRAIL, with the hope that this therapy would kill tumor cells but not normal cells in the A549 lung adenocarcinoma cell line. Whether XAF1 and TRAIL was able to kill lung tumor cells and induce cell apoptosis collaboratively or not was investigated, and the mechanism may provide a novel type of gene therapy in lung cancer.

TRAIL is a tumor-targeted therapy and its specific effect on killing tumor cells has been well-documented (15-17). At present, rhTRAIL alone or combined with chemotherapeutics for the treatment of various human tumors has progressed to phase III clinical trials and no obvious side effects has been observed. This indicates that TRAIL, as a tumor targeted therapy, possesses wide prospects for clinical application (18-20). XAF1 is able to significantly inhibit the growth of gastric cancer and enhance the apoptosis of gastric cancer cells, which prolonged the survival time of the mice under investigation when combined with TRAIL $(21,22)$. In this study, cell proliferation in the XAF1 + TRAIL group was significantly lower than in XAF1 group at the same concentration, while no difference was observed when compared with Null group. This indicates that TRAIL enhanced the killing effect of XAF1 on A549 lung adenocarcinoma cells. Furthermore, XAF1 alone was able to induce lung cancer cell apoptosis and 
A
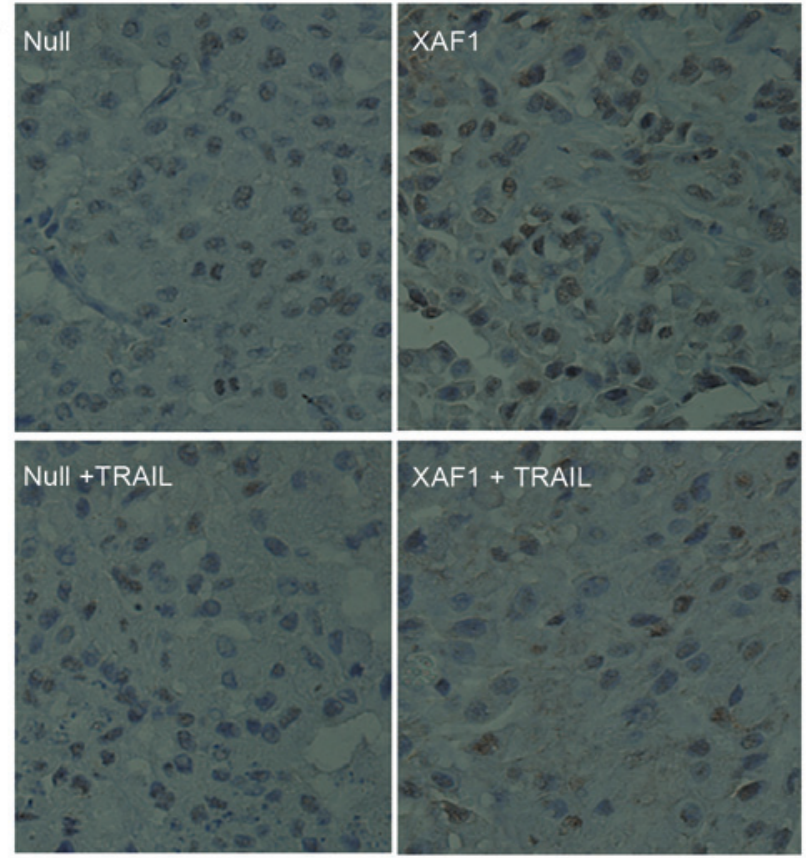

B

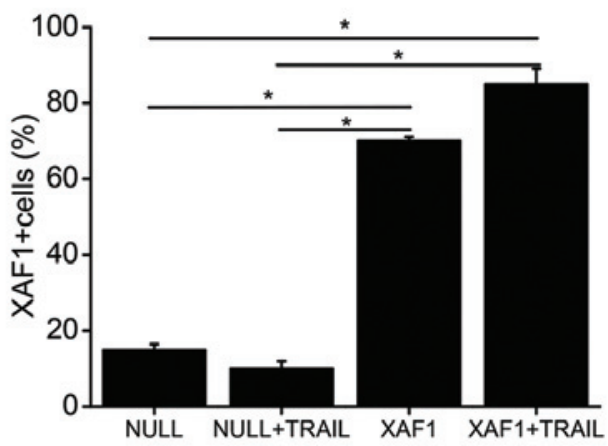

Figure 6. Expression of XAF1 in subcutaneous transplantation of nude mice. (A) Expression of XAF1 was assessed by immunohistochemical analysis (magnification, 40). (B) Quantitative analysis. "P<0.05.XAF1, X-linked inhibitor of apoptosis protein-associated factor 1; TRAIL, tumor necrosis factor-related apoptosis-inducing ligand.

promote apoptosis rates significantly when combined with TRAIL. There was no significant difference between the Null group and Null + TRAIL group, which indicates that XAF1 and TRAIL induce lung cancer cell apoptosis synergistically.

Apoptosis-related proteins have important roles in the progression of programmed cell death. Caspase-3, which is a member of the caspase family of 13 aspartate-specific cysteine proteases that have a central role in the execution of apoptotic mechanisms (23-25) is primarily responsible for the cleavage of PARP during cell death (26). PARP was suggested to contribute to cell death by depleting cells of NAD and ATP (27), as it is activated by binding to DNA ends or strand breaks. The present study investigated the effect of XAF1 and TRAIL on the growth of lung tumors in vivo and in vitro, and western blotting results confirmed that XAF1 and TRAIL led to activation of caspase-3 and PARP. This result indicates that the mechanism of XAF1 and TRAIL in inhibiting proliferation and inducing apoptosis in A549 lung adenocarcinoma cells is related to caspase-associated apoptosis signaling pathways.

In conclusion, XAF1 combined with TRAIL was able to significantly inhibit proliferation and induce apoptosis synergistically in lung cancer cells in vivo and in vitro. As TRAIL has been progressed to phase III clinical trials with preferably security, XAF1 + TRAIL may be a potential clinical therapy strategy for the treatment of lung cancer.

\section{Acknowledgements}

Not applicable.

\section{Funding}

The present study was supported by the Jiangsu Provincial Commission of Health and Family Planning (grant no. H201521), the Natural Science Foundation of Jiangsu Province (grant no. BK20161224), Science and Technology Research Foundation of Suzhou Municipality (grant no. SYS2018063), and the Youth Science and Technology Project of Suzhou Health and Family Planning Commission (grant no. KJXW2016016).

\section{Availability of data and materials}

The datasets used and/or analyzed during the current study are available from the corresponding author on reasonable request.

\section{Authors' contributions}

All authors contributed to designing the study, performing experiments, collecting and analyzing data and preparing the manuscript. All authors read and approved the final manuscript.

\section{Ethics approval and consent to participate}

All animal experiments were approved by and conducted according to the ethical guidelines of Medicine Laboratory Animal Ethics Committee of Shanghai Jiaotong School of Medicine (Shanghai, China).

\section{Patient consent for publication}

Not applicable.

\section{Competing interests}

The authors declare that they have no competing interests. 


\section{References}

1. Jemal A, Bray F, Center MM, Ferlay J, Ward E and Forman D: Global cancer statistics. CA Cancer J Clin 61: 69-90, 2011.

2. Lockshin RA and Williams CM: Programmed cell death-I. Cytology of degeneration in the intersegmental muscles of the Pernyi silkmoth. J Insect Physiol 11: 123-133, 1965.

3. Hanahan D and Weinberg RA: The hallmarks of cancer. Cell 100: 57-70, 2000

4. Yan F, Gou L, Yang J, Chen L, Tong A, Tang M, Yuan Z, Yao S, Zhang P and Wei Y: A novel pro-apoptosis gene PNAS4 that induces apoptosis in A549 human lung adenocarcinoma cells and inhibits tumor growth in mice. Biochimie 91: 502-507, 2009

5. Yang WT, Chen DL, Zhang FQ, Xia YC, Zhu RY, Zhou DS and Chen YB: Experimental study on inhibition effects of the XAF1 gene against lung cancer cell proliferation. Asian Pac J Cancer Prev 15: 7825-7829, 2014.

6. Yang WT, Chen DL, Zhang FQ, Xia YC, Zhu RY, Zhou DS and Chen YB: Experimental study on inhibition effects of the XAF1 gene against lung cancer cell proliferation. Asian Pac J Cancer Prev 15: 7825-7829, 2014

7. Ashkenazi A, Pai RC, Fong S, Leung S, Lawrence DA, Marsters SA, Blackie C, Chang L, McMurtrey AE, Hebert A, et al: Safety and antitumor activity of recombinant soluble Apo2 ligand. J Clin Invest 104: 155-162, 1999.

8. Hao C, Song JH, Hsi B, Lewis J, Song DK, Petruk KC, Tyrrell DL and Kneteman NM: TRAIL inhibits tumor growth but is nontoxic to human hepatocytes in chimeric mice. Cancer Res 64 8502-8506, 2004

9. Lawrence D, Shahrokh Z, Marsters S, Achilles K, Shih D, Mounho B, Hillan K, Totpal K, DeForge L, Schow P, et al: Differential hepatocyte toxicity of recombinant Apo2L/TRAIL versions. Nat Med 7: 383-385, 2001

10. Arrieta O, Saavedra-Perez D, Kuri R, Aviles-Salas A, Martinez L, Mendoza-Posada D, Castillo P, Astorga A, Guzman E and De la Garza J: Brain metastasis development and poor survival associated with carcinoembryonic antigen (CEA) level in advanced non-small cell lung cancer: A prospective analysis. BMC Cancer 9: 119, 2009.

11. Brown JM and Attardi LD: The role of apoptosis in cancer development and treatment response. Nat Rev Cancer 5: 231-237, 2005.

12. Liston P, Fong WG and Korneluk RG: The inhibitors of apoptosis: There is more to life than Bcl2. Oncogene 22: 8568-8580, 2003.

13. Straszewski-Chavez SL, Visintin IP, Karassina N, Los G, Liston P, Halaban R, Fadiel A and Mor G: XAF1 mediates tumor necrosis factor-alpha-induced apoptosis and X-linked inhibitor of apoptosis cleavage by acting through the mitochondrial pathway. J BiolChem 282: 13059-13072, 2007.

14. Fong WG, Liston P, Rajcan-Separovic E, St Jean M, Craig C and Korneluk RG: Expression and genetic analysis of XIAP-associated factor 1 (XAF1) in cancer cell lines. Genomics 70: 113-122, 2000.
15. Finnberg N and El-Deiry WS: Selective TRAIL-induced apoptosis in dysplastic neoplasia of the colon may lead to new neoadjuvant or adjuvant therapies. Clin Cancer Res 12: 4132-4136, 2006

16. Jalving M, de Jong S, Koornstra JJ, Boersma-van Ek W, Zwart N, Wesseling J, de Vries EG and Kleibeuker JH: TRAIL induces apoptosis in human colorectal adenoma cell lines and human colorectal adenomas. Clin Cancer Res 12: 4350-4356, 2006.

17. Zhang L and Fang B: Mechanisms of resistance to TRAIL-induced apoptosis in cancer. Cancer Gene Ther 12: 228-237, 2005.

18. Herbst RS, Mendolson DS, Ebbinghaus S, Gordon MS, O'Dwyer P, Lieberman G, Ing J, Kurzrock R, Novotny W and Eckhardt G: A phase I safety and pharmacokinetic (PK) study of recombinant Apo2L/TRAIL, an apoptosis-inducing protein in patients with advanced cancer. J ClinOncol 24: 124, 2006.

19. Soria JC, Mark Z, Zatloukal P, Szima B, Albert I, Juhász E, Pujol JL, Kozielski J, Baker N, Smethurst D, et al: Randomized phase II study of dulanermin in combination with paclitaxel, carboplatin, and bevacizumab in advanced non-small-cell lung cancer. J Clin Oncol 29: 4442-4451, 2011.

20. Yee L, Fanale M, Dimick K, Calvert S, Robins C, Ing J, Ling J, Novotny W, Ashkenazi A and Burris H: A phase IB safety and pharmacokinetic (PK) study of recombinant human Apo2L/TRAIL in combination with rituximab in patients with low-grade non-Hodgkin lymphoma. J ClinOncol 25: 8078, 2007.

21. Tu SP, Liston P, Cui JT, Lin MC, Jiang XH, Yang Y, Gu Q, Jiang SH, Lum CT, Kung HF, et al: Restoration of XAF1 expression induces apoptosis and inhibits tumor growth in gastric cancer. Int J Cancer 125: 688-697, 2009.

22. Tu SP, Sun YW, Cui JT, Zou B, Lin MC, Gu Q, Jiang SH, Kung HF, Korneluk RG and Wong BC: Tumor suppressor XIAP-associated factor 1 (XAF1) cooperates with tumor necrosis factor-related apoptosis-inducing ligand to suppress colon cancer growth and trigger tumor regression. Cancer 116: 1252-1263, 2010.

23. Alnemri ES, Livingston DJ, Nicholson DW, Salvesen G, Thornberry NA, Wong WW and Yuan J: Human ICE/CED-3 protease nomenclature. Cell 87: 171, 1996.

24. Cohen GM: Caspases: The executioners of apoptosis. Biochem J 326: 1-16, 1997.

25. Wang $\mathrm{J}$ and Lenardo MJ: Roles of caspases in apoptosis, development, and cytokine maturation revealed by homozygous gene deficiencies. J Cell Sci 113: 753-757, 2000.

26. Tewari M, QuanLT,O'RourkeK,Desnoyers S,ZengZ,BeidlerDR, Poirier GG, Salvesen GS and Dixit VM: Yama/CPP32beta, a mammalian homolog of CED-3, is a CrmA-inhibitable protease that cleaves the death substrate poly(ADP-ribose) polymerase. Cell 81: 801-809, 1995.

27. Virág L, Robaszkiewicz A, Rodriguez-Vargas JM and Oliver FJ: Poly(ADP-ribose) signaling in cell death. Mol Aspects Med 34: 1153-1167, 2013. 